\title{
François Villon, Lais, Testament, Poésies diverses
}

\section{Maria Colombo Timelli}

\section{Q OpenEdition}

\section{Journals}

\section{Édition électronique}

URL : http://journals.openedition.org/studifrancesi/32862

DOI : 10.4000/studifrancesi.32862

ISSN : 2427-5856

Éditeur

Rosenberg \& Sellier

\section{Édition imprimée}

Date de publication : 1 décembre 2005

Pagination : 618

ISSN : 0039-2944

\section{Référence électronique}

Maria Colombo Timelli, «François Villon, Lais, Testament, Poésies diverses », Studi Francesi [En ligne], 147 (XLX | III) | 2005, mis en ligne le 30 novembre 2015, consulté le 18 avril 2021. URL : http:// journals.openedition.org/studifrancesi/32862 ; DOI : https://doi.org/10.4000/studifrancesi.32862

\section{Ce document a été généré automatiquement le 18 avril 2021.}

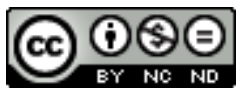

Studi Francesi è distribuita con Licenza Creative Commons Attribuzione - Non commerciale - Non opere derivate 4.0 Internazionale. 


\title{
François Villon, Lais, Testament, Poésies diverses
}

\author{
Maria Colombo Timelli
}

\section{RÉFÉRENCE}

FRANÇOIS VILLON, Lais, Testament, Poésies diverses. Edition bilingue. Publication, traduction, présentation et notes par JEAN-CLAUDE MÜHLETHALER, avec Ballades en Jargon. Edition bilingue. Publication, traduction, présentation et notes par ERIC HICKS, Paris, Champion, 2004 («Champion Classiques. Moyen Age», 10), 469 pp.

1 L'œuvre de François Villon est aujourd'hui facilement accessible même au grand public grâce à des éditions accompagnées de notes et de traductions en français moderne: pour nous en tenir aux plus récentes, il suffira de rappeler l'édition fournie par Claude Thiry en 1991 («Lettres Gothiques»), et celle de Jean Dufournet (Garnier-Flammarion 1992, première édition 1984). Il s'agit donc d'abord, pour Jean-Claude Mühlethaler, qui signe la présentation de la première partie, de justifier cette nouvelle édition, qui a en effet le mérite de faire le point des études les plus récentes suscitées par le poète en tenant compte en plus de la publication, au cours de ces vingt dernières années, d'un certain nombre d'œuvres du $\mathrm{XV}^{\mathrm{e}}$ siècle jusqu'ici peu connues, qui enrichissent indubitablement la toile de fond, le contexte culturel et littéraire où la production poétique villonienne se situe (on se rapportera à la bibliographie, pp. 31-42, nécessairement sélective, à intégrer avec les nombreux travaux cités dans les notes).

2 L'Introduction de Mühlethaler (pp. 7-42) aborde deux problèmes auxquels la critique se confronte depuis toujours: la question biographique et le rapport de Villon avec Paris. Malgré quelques documents conservés, la chronologie de la vie du poète demeure floue; surtout, même si Villon n'a pas hésité à se mettre en scène dans son œuvre comme peu d'écrivains de son temps l'ont fait, ce sont l'ironie et l'intention ludique qui priment et qui couvrent, par conséquent, la 'réalité' des faits et des personnes; la conservation même de quelques autographes (autre fait rare à la fin du Moyen Age) ne contribue pas 
non plus à notre connaissance de l'auteur. Des considérations analogues s'imposent pour le rapport qui lie François Villon à Paris et aux personnages réels qu'il cite abondamment. Certes, les recherches des érudits (dont celles, fondamentales, de Pierre Champion) ont levé un coin du voile, parfois beaucoup plus, mais les noms évoqués n'échappent pas au jeu et aux réseaux d'association: la connotation l'emporte toujours sur la simple dénotation. L'édition du Lais et du Testament s'appuie sur le manuscrit $C$ (BnF, fr. 20041), suivi très fidèlement; pour les Poésies diverses, on a eu recours au même manuscrit $C$, au ms. $O$ (Charles d'Orléans), au «chansonnier de Rohan» (ms. H), au ms. Ch1 (Fais maistre Alain Chartier), et à l'édition Vérard, ca. 1501, du Jardin de Plaisance (appelé étonnamment «ms. J» à la p. 334). La traduction en français moderne, qui sans être littérale s'efforce de suivre la phrase originale, est publiée en regard. Le texte est accompagné d'un apparat complémentaire imposant: si les Variantes et leçons rejetées ne susciteront que l'intérêt des philologues et des spécialistes, les Notes, manifestement destinées à l'ensemble des lecteurs, permettront une meilleure compréhension de tous les aspects à peine obscurs du texte: on y trouvera la discussion de questions d'ordre linguistique et littéraire et de problèmes liés à la traduction, des renvois biliographiques ponctuels, ainsi que les commentaires fournis par Clément Marot en 1533 et les notes de Lenglet-Dufresnoy (1732-1744). Un petit glossaire est donné en plus aux pp. 369-378.

3 Une Introduction à part, par Eric Hicks (décédé en janvier 2004, peu avant la parution du livre), présente les problèmes majeurs des onze Ballades en jargon (pp. 379-389): y sont discutés la langue et la possibilité d'offrir une traduction, d'un côté, l'attribution des poèmes à Villon, de l'autre. Sans pouvoir trancher sur cette dernière question, Erik Hicks conclut prudemment que «le jargon appartient à l'esprit de Villon. Il ne peut que gagner à être lu dans le contexte des œuvres majeures du poète» (p. 387).

L'Index des noms propres, aux pp. 437-466, fournit des informations synthétiques mais tout à fait bienvenues pour éclairer le lecteur.

Tout en reconnaissant la valeur de cette édition, et le remarquable résultat obtenu dans la traduction par deux spécialistes de la poésie du XVe siècle, nous nous permettons une petite remarque d'ordre bibliographique; en plus du Dictionnaire des locutions de Giuseppe Di Stefano (1991), nous disposons aujourd'hui de deux autres outils capables de jeter une lumière plus complète sur certains jeux de la langue de François Villon: le Dictionnaire érotique. Ancien français, moyen français, Renaissance de Rose M. Bidler (Montréal, 2002), utile pour l'ensemble de la production villonienne, et le Thesaurus Proverbiorum Medii Ævi (Berlin - New York, De Gruyter, 1995-2002), qui fournirait sans doute quelques renvois de plus pour des poèmes tels que la Ballade des contre-vérités, la Ballade des proverbes ou encore la Ballade des menus propos. 